\title{
Genetic consequences of postglacial colonization by the endemic Yarkand hare (Lepus yarkandensis) of the arid Tarim Basin
}

\author{
SHAN WenJuan ${ }^{1,2^{*}}$, LIU Jiang ${ }^{2,3^{*}}$, YU Li $^{2}$, ROBERT W. Murphy ${ }^{3,4}$, MAHMUT Halik $^{1 \dagger} \&$ \\ ZHANG YaPing $2,3 \nmid$ \\ ${ }^{1}$ College of Life Sciences and Technology, Xinjiang University, Urumqi 830046, China; \\ ${ }^{2}$ Laboratory for Conservation and Utilization of Bio-resource \& Key Laboratory for Microbial Resources of the Ministry of Education, Yunnan \\ University, Kunming 650091, China; \\ ${ }^{3}$ State Key Laboratory of Genetic Resources and Evolution, Kunming Institute of Zoology, Kunming 650223, China; \\ ${ }^{4}$ Centre for Biodiversity and Conservation Biology, Royal Ontario Museum, Ontario M5S 2C6, Canada
}

Received November 9, 2010; accepted February 28, 2011

\begin{abstract}
Orogenesis of the Qinghai-Tibetan Plateau, which occurred in a stepwise manner, contributed to the extreme aridity of the Tarim Basin, resulting in vulnerable and unstable ecosystems. Quaternary climatic oscillations may have affected the ecosystems and, consequently, the distributions and genetic structuring of the Tarim Basin's biota. We used nucleotide sequence data from 2 mitochondrial (mt) DNA genes (Cyt $b$ and the D-loop) to test hypotheses associated with the matrilineal and demographical histories of the Tarim Basin's endemic Yarkand hare (Lepus yarkandensis). Range-wide sampling involving 20 populations and 224 individuals detected 126 haplotypes that clustered into 5 major lineages in both the phylogenetic tree and median-joining network. Populations from the northern and eastern Tarim Basin shared a similar history, as did those from the western and southern regions. Demographical analysis and genetic diversity estimations suggested that the western and southern regions might have served as glacial refugia for the Yarkand hare during Quaternary climatic oscillations. The distribution of the Yarkand hare, especially in the northern and eastern parts, probably represented 3 postglacial colonization events, dated to $0.21,0.090$ and 0.054 MYA, which corresponded to known interglacial periods. Given the relatively complete geographic isolation between the eastern and southern populations, the Yarkand hare likely dispersed during postglacial periods from the southwest to the north, and then onward to the east. The absence of water likely forced the species into refugia, and this differed from other Pleistocene biogeographical drivers. The demographical and historical patterns have important implications for conservation.
\end{abstract}

mtDNA, glacial refugia, Quaternary, Pleistocene, Qinghai-Tibetan Plateau, conservation, Lagomorpha, Leporidae

Citation: Shan W J, Liu J, Yu L, et al. Genetic consequences of postglacial colonization by the endemic Yarkand hare (Lepus yarkandensis) of the arid Tarim Basin. Chinese Sci Bull, 2011, 56: 1370-1382, doi: 10.1007/s11434-011-4460-9

Pleistocene climatic changes imposed significant range shifts on many Palearctic biota, and contributed to their demographic history and genetic diversity [1]. Many temperate species existed only in refugia at times of glacial maxima, and recolonized or expanded into newly available habitats during interglacial periods [2,3]. Quaternary evolutionary histories of European and North American biota

*These authors contributed equally to this work

†Corresponding authors (email: zhangyp@mail.kiz.ac.cn; mahmuthalic@xju.edu.cn) have been well documented [4-13]. In contrast, studies on the Asian biota have been rather limited. The complex topography of East Asia probably provided refugia for species during times of Pleistocene glaciation [14], yet only a few plant and bird species restricted to the Qinghai-Tibetan Plateau (QTP) have been evaluated [15-20].

Orogenesis of the QTP affected surrounding ecologies. For example, genealogical evaluations of largely aquatic frogs are associated with changes in river courses [21]. The phylogenetic history of Southeast Asian frogs in the tribe 
Paini was greatly affected by the Cenozoic Indo-Asian collision that resulted in the uplift of the QTP [22]. Other surrounding regions, such as the Tarim Basin, may have been similarly affected.

The Tarim Basin is located on the northern edge of the QTP in southern Xinjiang Uygur Autonomous Region, northwestern China (Figure 1). With an area of $\sim 560000$ $\mathrm{km}^{2}$, it is the world's largest inland basin. To the north, it is bounded by the Tianshan Mountains, to the south by the Kunlun Mountains, to the west by the Pamir Plateau, and to the southeast by the Altun Mountains. The elevations in the basin range from 800 to $1300 \mathrm{~m}$ above sea level (a.s.l), whereas the average height of the surrounding mountains exceeds $4000 \mathrm{~m}$ a.s.l. The Taklamakan Desert (337000 $\mathrm{km}^{2}$ ), which dominates much of the Tarim Basin, is encircled by intermittent oases. Being extremely arid, the basin's ecosystem is vulnerable and unstable [23-26]. During the Quaternary, montane glaciers surrounded the Tarim Basin, but these were absent within the Tarim Basin itself [27-32]. To what extent, if any, was the biota in the Tarim Basin affected by Quaternary glacial cycles?

The Yarkand hare (Lepus yarkandensis) only is associated with the system of oases that encircle the Taklamakan Desert [33]. It is smaller than other species of Chinese hares, and it appears to have adapted to tolerating extreme environmental stress. Populations of Yarkand hares are in decline because desert encroachment and human activities [34]. It is listed in the Second Category of State Key Protected Wildlife List (1988), and as Near Threatened in the 1996 IUCN Red List of Threatened Animals [35].
The Yarkand hare is a model organism for studying the effects of Quaternary climatic oscillations on the Tarim Basin biota. It speciated around $0.64 \pm 0.26$ million years ago (MYA) [36] and successfully survived the Quaternary. Although several species of Lepus were greatly affected by Pleistocene climatic fluctuations [11,36-40], the impact of climatic oscillations on the demographic history and genetic diversity of the Yarkand hare is poorly understood [41,42]. Consequently, we analyzed mitochondrial DNA diversity from the species. Our primary null hypothesis $\left(H_{0 \text { ran }}\right)$ states that genetic structuring is random, other than isolation by distance, and genetic diversity is equally distributed across the range. Several associated secondary null hypotheses are noted below.

\section{Materials and methods}

\subsection{Sample collection and laboratory methods}

A total of 224 skin or muscle samples from Yarkand hares were obtained from 20 localities in the Tarim Basin, which almost completely covered the species range (Figure 1 and Table S1). All collections were performed following animal use protocols approved by the Kunming Institute of Zoology Animal Care Committee.

Total DNA was extracted following standard procedures using proteinase $\mathrm{K}$ [43]. The complete Cytochrome oxidase $b$ (Cyt $b$ ) gene and control region (D-loop) were amplified from all samples using degenerate primers. Primer pair 5'-CAACTACAAGAACCTAATG-3' (forward primer) and

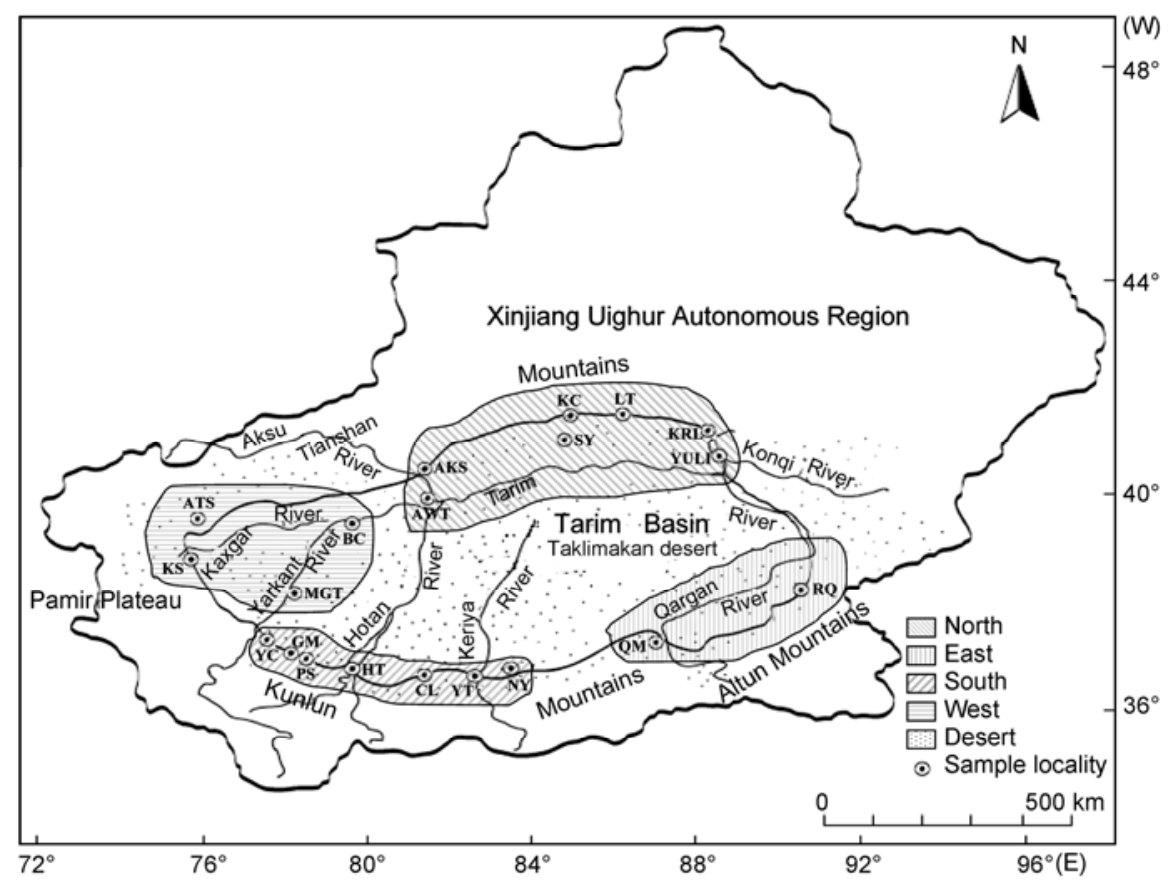

Figure 1 Geographical distribution of 20 sampling localities and the distribution of the Yarkand hare, Lepus yarkandensis. Locality abbreviations are detailed in Table S1. 
5'-CAGGGTAATAYACTATACTA-3' (reverse primer) were used for Cyt $b$, and 5'-CAGAGATGGAGATYAACTC-3' (forward primer) and 5'-GCATGGGCTGATTAGTCAT-3' (reverse primer) for the D-loop. PCR amplification was performed as follows: $95^{\circ} \mathrm{C}$ initial hot start for $5 \mathrm{~min}$; followed by 35 cycles of $94^{\circ} \mathrm{C}$ denaturation for $1 \mathrm{~min}, 51^{\circ} \mathrm{C}$ annealing for $1 \mathrm{~min}$ and $72^{\circ} \mathrm{C}$ extension for $1 \mathrm{~min}$. A final extension was made at $72^{\circ} \mathrm{C}$ for $10 \mathrm{~min}$. Amplified PCR products were purified and then sequenced in both directions on an ABI PRISM ${ }^{\text {TM }} 3730$ DNA sequencer, following the manufacturer's protocols. All sequences obtained were checked carefully for ambiguous scores and then queried by BLAST searches against GenBank to confirm homology [44]. The sequences were deposited in GenBank with the accessions [HM752273-HM752352] for Cyt $b$ and [HM752353-HM752460] for D-loop.

\subsection{Data analyses}

The Cyt $b$ and D-loop sequences were initially aligned using ClustalX 1.81 [45] and subsequently refined by visual inspection. Nucleotide diversity $(\pi)$ and haplotype diversity (h) were determined using ARLEQUIN v.3.1 [46]. The Yarkand hare is very mobile; therefore, the 20 populations were divided into four geographical groups according to the potential river and desert barriers (Figure 1). Each group was analyzed separately as follows: North (KC, SY, LT, KRL, YULI, AKS and AWT); East (RQ and QM); West (ATS, KS, BC and MGT); and South (YC, PS, GM, HT, CL, YT and NY). To examine genetic differentiation among these groups, pairwise $F_{\mathrm{ST}}$ values were calculated and tested for significance using ARLEQUIN; Cyt $b$ and D-loop were evaluated independently.

To detect haplotypic differentiation in the Yarkand hare, a median-joining network (MJN) was constructed with the software NETWORK 4.1.0.9 [47], based on concatenated Cyt $b$ and D-loop sequences. This method outperforms minimum-spanning networks and statistical parsimony methods when networks have relatively divergent haplotypes and are characterized by numerous missing-node haplotypes [48], which was true for Yarkand hares. Analysis of molecular variance [49] (AMOVA; 10000 permutations) was computed to test for population structure using ARLEQUIN.

Possible historical population expansion events were assessed by mismatch distribution and Fu's $F_{\mathrm{S}}$ value [50] using ARLEQUIN. Populations at demographic equilibrium, the null hypothesis $\left(H_{0 \mathrm{eq}}\right)$, were expected to show a multimodal distribution, and, alternatively $\left(H_{1 \mathrm{eq}}\right)$, populations that experienced a recent demographic expansion were expected to be unimodal [51]. Demographic expansion time was estimated from Cyt $b$ sequences using the equations $\tau=$ $2 u t$ and $u=\mu k$, where $\mu$ was the mutation rate for the whole sequence, $t$ was the number of generations since the expansion, and $k$ was the length of sequence used. A Cyt $b$ diver- gence rate of $4 \%$ per MYA was assumed [36]. For the $F_{\mathrm{S}}$ analyses, significance was based on 5000 simulated samplings.

The matrilineal history of the Yarkand hare was hypothesized using Bayesian inference as implemented in MrBayes v. 3.04b [52]. Lepus hainanus from [37] and Oryctolagus cuniculus from [38] were used as the outgroup. The program MODELTEST 3.7 [53] was used to find the optimal model of DNA substitution based on the Akaike information criterion [54]. Bayesian analyses began with random starting trees and ran for $5 \times 10^{6}$ generations, with Markov chains sampled every 100 generations. The first $1.25 \times 10^{6}$ generations were discarded as burn-in. The analysis was conducted twice to ensure that the Bayesian analyses were not trapped in local optima $[55,56]$. The remaining trees from both analyses were used to create a majority rule consensus tree, where the percent of samples recovering the same clade was assumed to represent the Bayesian posterior probability (BPP) of that clade.

Nodal support based on nonparametric bootstrap sampling (BS) used 1000 pseudoreplicates. The analysis was performed on a neighbor-joining (NJ) phenogram calculated using MEGA 4 [57]. Gaps and missing data were excluded in the NJ analysis, and the Maximum Composite Likelihood model was used for calculating genetic distances. Uncorrected genetic distances ( $\mathrm{p}$-distance) between, and within, major mtDNA lineages were calculated based on Cyt $b$ data using MEGA 4 [57].

\section{Results}

\subsection{Sequence diversity}

A total of 224 sequences consisting of 1140 base pairs were aligned for Cyt $b$. The average base frequencies were as follows: $\mathrm{A}=28.6 \%, \mathrm{G}=12.5 \%, \mathrm{C}=27.5 \%$ and $\mathrm{T}=31.4 \%$. Nine transitions and one transversion were identified. Eighty haplotypes were discovered based on 107 polymorphic sites, of which 53 were potentially phylogenetically informative. The Cyt $b$ sequences appeared to be of mitochondrial origin and not nuclear mitochondrial pseudogenes (numts), as the reading frame was intact and the third position base composition $(\mathrm{A}=36.4 \%, \mathrm{C}=32.6 \%, \mathrm{G}=2.0 \%$ and $\mathrm{T}=29 \%$ ) was similar to the average in mammalian mtDNA [58] ( $\mathrm{A}=39 \%, \mathrm{C}=36 \%, \mathrm{G}=3 \%$ and $\mathrm{T}=21 \%)$. For the D-loop, an alignment length of 553 base pairs was obtained for 224 fragments. The average base frequencies were as follows: A $=29.1 \%, \mathrm{G}=11.4 \%, \mathrm{C}=30.5 \%$ and $\mathrm{T}=29 \%$. Seventeen transitions and three transversions were identified. A total of 106 haplotypes were defined from 106 polymorphic sites, of which 93 were potentially phylogenetically informative. After concatenating the Cyt $b$ and D-loop fragments (1693 bp (aligned)), 126 haplotypes were identified. Among 213 polymorphic sites, 146 were potentially phylogenetically informative. Separate phylogenetic analysis of Cyt $b$ and 
Table 1 Estimates of sequence diversity in the Yarkand hare (Lepus yarkandensis) based on the separate analyses of two mtDNA genes, Cyt $b$ and the D-loop, and by geographic grouping ${ }^{\text {a) }}$

\begin{tabular}{|c|c|c|c|c|c|c|}
\hline Group & Localities & $n$ & Gene & $n H$ & $\pi \pm \mathrm{SD}$ & $h \pm \mathrm{SD}$ \\
\hline \multirow[t]{16}{*}{ North } & & 117 & D-loop & 61 & $0.030 \pm 0.015$ & $0.981 \pm 0.005$ \\
\hline & & & Cyt $b$ & 48 & $0.005 \pm 0.003$ & $0.944 \pm 0.013$ \\
\hline & $\mathrm{KC}$ & 14 & D-loop & 12 & $0.021 \pm 0.012$ & $0.978 \pm 0.035$ \\
\hline & & & Cyt $b$ & 10 & $0.003 \pm 0.002$ & $0.945 \pm 0.045$ \\
\hline & SY & 6 & D-loop & 6 & $0.029 \pm 0.017$ & $1.000 \pm 0.096$ \\
\hline & & & Cyt $b$ & 4 & $0.003 \pm 0.002$ & $0.867 \pm 0.130$ \\
\hline & $\mathrm{LT}$ & 47 & D-loop & 24 & $0.028 \pm 0.014$ & $0.967 \pm 0.010$ \\
\hline & & & Cyt $b$ & 21 & $0.004 \pm 0.002$ & $0.933 \pm 0.010$ \\
\hline & KRL & 28 & D-loop & 19 & $0.032 \pm 0.017$ & $0.957 \pm 0.022$ \\
\hline & & & Cyt $b$ & 15 & $0.006 \pm 0.003$ & $0.915 \pm 0.032$ \\
\hline & YULI & 7 & D-loop & 5 & $0.020 \pm 0.012$ & $0.857 \pm 0.137$ \\
\hline & & & Cyt $b$ & 5 & $0.003 \pm 0.002$ & $0.905 \pm 0.010$ \\
\hline & AKS & 7 & D-loop & 7 & $0.016 \pm 0.010$ & $1.000 \pm 0.076$ \\
\hline & & & Cyt $b$ & 5 & $0.002 \pm 0.001$ & $0.857 \pm 0.137$ \\
\hline & AWT & 8 & D-loop & 7 & $0.020 \pm 0.019$ & $0.964 \pm 0.077$ \\
\hline & & & Cyt $b$ & 6 & $0.006 \pm 0.004$ & $0.893 \pm 0.111$ \\
\hline \multirow[t]{6}{*}{ East } & & 18 & D-loop & 15 & $0.035 \pm 0.018$ & $0.974 \pm 0.029$ \\
\hline & & & Cyt $b$ & 11 & $0.006 \pm 0.003$ & $0.915 \pm 0.050$ \\
\hline & RQ & 14 & D-loop & 12 & $0.035 \pm 0.019$ & $0.967 \pm 0.044$ \\
\hline & & & Cyt $b$ & 10 & $0.006 \pm 0.003$ & $0.923 \pm 0.060$ \\
\hline & QM & 4 & D-loop & 3 & $0.036 \pm 0.025$ & $0.833 \pm 0.222$ \\
\hline & & & Cyt $b$ & 3 & $0.006 \pm 0.005$ & $0.833 \pm 0.222$ \\
\hline \multirow[t]{10}{*}{ West } & & 27 & D-loop & 20 & $0.029 \pm 0.015$ & $0.974 \pm 0.017$ \\
\hline & & & Cyt $b$ & 12 & $0.011 \pm 0.006$ & $0.909 \pm 0.031$ \\
\hline & ATS & 2 & D-loop & 2 & $0.048 \pm 0.049$ & $1.000 \pm 0.500$ \\
\hline & & & Cyt $b$ & 2 & $0.018 \pm 0.019$ & $1.000 \pm 0.500$ \\
\hline & KS & 17 & D-loop & 12 & $0.029 \pm 0.016$ & $0.956 \pm 0.033$ \\
\hline & & & Cyt $b$ & 10 & $0.012 \pm 0.007$ & $0.897 \pm 0.056$ \\
\hline & $\mathrm{BC}$ & 6 & D-loop & 6 & $0.025 \pm 0.015$ & $1.000 \pm 0.096$ \\
\hline & & & Cyt $b$ & 6 & $0.005 \pm 0.003$ & $1.000 \pm 0.096$ \\
\hline & MGT & 2 & D-loop & 2 & $0.036 \pm 0.037$ & $1.000 \pm 0.500$ \\
\hline & & & Cyt $b$ & 2 & $0.022 \pm 0.022$ & $1.000 \pm 0.500$ \\
\hline \multirow[t]{16}{*}{ South } & & 62 & D-loop & 23 & $0.032 \pm 0.016$ & $0.920 \pm 0.016$ \\
\hline & & & Cyt $b$ & 22 & $0.010 \pm 0.005$ & $0.916 \pm 0.017$ \\
\hline & $\mathrm{YC}$ & 1 & D-loop & 1 & N.A & N.A \\
\hline & & & Cyt $b$ & 1 & N.A & N.A \\
\hline & PS & 7 & D-loop & 3 & $0.020 \pm 0.011$ & $0.524 \pm 0.209$ \\
\hline & & & Cyt $b$ & 4 & $0.010 \pm 0.006$ & $0.714 \pm 0.181$ \\
\hline & GM & 4 & D-loop & 4 & $0.021 \pm 0.015$ & $1.000 \pm 0.177$ \\
\hline & & & Cyt $b$ & 4 & $0.011 \pm 0.008$ & $1.000 \pm 0.177$ \\
\hline & HT & 43 & D-loop & 15 & $0.032 \pm 0.016$ & $0.878 \pm 0.027$ \\
\hline & & & Cyt $b$ & 13 & $0.009 \pm 0.005$ & $0.866 \pm 0.027$ \\
\hline & CL & 2 & D-loop & 2 & $0.028 \pm 0.029$ & $1.000 \pm 0.500$ \\
\hline & & & Cyt $b$ & 2 & $0.011 \pm 0.012$ & $1.000 \pm 0.500$ \\
\hline & $\mathrm{YT}$ & 4 & D-loop & 4 & $0.026 \pm 0.018$ & $1.000 \pm 0.177$ \\
\hline & & & Cyt $b$ & 4 & $0.008 \pm 0.006$ & $1.000 \pm 0.177$ \\
\hline & NY & 1 & D-loop & 1 & N.A & N.A \\
\hline & & & Cyt $b$ & 1 & N.A & N.A \\
\hline \multirow[t]{2}{*}{ Total } & & 224 & D-loop & 108 & $0.033 \pm 0.016$ & $0.986 \pm 0.002$ \\
\hline & & & Cyt $b$ & 80 & $0.008 \pm 0.004$ & $0.969 \pm 0.005$ \\
\hline
\end{tabular}

a) Locality abbreviations refer to Table S1. $n=$ sample size; $n H=$ number of haplotypes; $\pi=$ nucleotide diversity; $h=$ haplotype diversity; SD $=$ standard deviation. Bold numbers indicate group averages. 
D-loop found similar phylogenetic trees, suggesting that the D-loop fragment was also from mtDNA.

Nucleotide diversity values $(\pi)$ ranged from $0.016 \pm$ 0.010 (AKS) to $0.048 \pm 0.049$ (ATS) in the D-loop, and from $0.002 \pm 0.001$ (AKS) to $0.022 \pm 0.022$ (MGT) in Cyt $b$ (Table 1); $\pi$ averaged $0.033 \pm 0.016$ for the D-loop and $0.008 \pm 0.004$ for Cyt $b$. Among the 4 geographical groups, $\pi$ for the D-loop showed no significant differences. In contrast, $\pi$ values for Cyt $b$ in the West $(0.011 \pm 0.006)$ and South $(0.010 \pm 0.005)$ were almost twice as high as those observed in the North $(0.005 \pm 0.003)$ and East $(0.006 \pm$ $0.003)$. Haplotype diversity values $(h)$ for the D-loop ranged from $0.524 \pm 0.209$ (PS) to $1.000 \pm 0.500$ (ATS, MGT, and $\mathrm{CL}$ ), and for Cyt $b$ from $0.714 \pm 0.181$ (PS) to $1.000 \pm$ 0.500 (ATS, MGT, and CL). Averaged across all populations, $h$ for the D-loop was $0.986 \pm 0.002$ and for Cyt $b$ was $0.969 \pm 0.005$. Values of $h$ for both D-loop and Cyt $b$ were very high $(>0.9)$ and the 4 geographical groups showed no obvious differences.

\subsection{Network analysis and population differentiation}

The MJN resolved 5 haplogroups, which were referred to as groups A, B, C, D and E (Figure 2). Group A included 60 haplotypes, of which 10 were from West (7) or South (3), 46 were from East (5) or North (41). Haplotypes H14 and H37 were shared by West and North, and H28 and H57 were shared by South and North. The 18 haplotypes of B were from West (3), South (13), North (1; H79), and one was shared by West and North (H83). Most of the 29 haplotypes in C were from East (7), North (18), or shared between them $(1 ; \mathrm{H} 115)$, but the group also included South (3). The 7 haplotypes in D included South (2), North (2), and East (2), and one shared by North and East (H23). Group E had 12 haplotypes in total from West (9), South (2), and North (1). Most haplotypes from East and North were admixed and fell within groups $\mathrm{A}$ and $\mathrm{C}$, and the majority of haplotypes from West and South were admixed and fell within groups B and E. Group D included a small number of haplotypes from South, North and East, but not West, and none of these haplotypes dominated in any region.

For AMOVA, we divided the 20 populations into 2 groups according to geographical associations in the MJN (Figure 2). One group combined populations in North and East and other included populations in West and South. The results partitioned variation in the D-loop to $5.82 \%$ $\left(F_{\mathrm{CT}}=0.058, P<0.001\right)$ occurring among groups, $11.24 \%$ $\left(F_{\mathrm{SC}}=0.119, P<0.001\right)$ for among populations within groups, and $82.94 \% \quad\left(F_{\mathrm{ST}}=0.171, P<0.001\right)$ to occurring within populations. Similarly, $11.28 \%$ of the variation in Cyt $b$ $\left(F_{\mathrm{CT}}=0.11, P<0.001\right)$ was explained by differences among groups, $12.81 \%\left(F_{\mathrm{SC}}=0.14, P<0.001\right)$ by among populations within groups, and $75.90 \%\left(F_{\mathrm{ST}}=0.244, P<0.001\right)$ within sampled populations (Table 2). For the D-loop, South and
West had the lowest pairwise $F_{\mathrm{ST}}$ value $(0.066)$, while East and West had the highest pairwise $F_{\text {ST }}$ value (0.130). Similarly, for Cyt $b$, South and West also had the lowest pairwise $F_{\mathrm{ST}}$ value $(0.104)$, and North and West had the highest (0.246). Overall, the pairwise $F_{\mathrm{ST}}$ values between North and East and between South and West were relatively lower than the others (Table 3 ). These analyses required rejection of $H_{0 \text { ran }}$ and acceptance of the alternative hypothesis, $H_{1 \text { ran }}$, which stated that genetic diversity was not randomly distributed.

\subsection{Demographic analysis}

Given that the D-loop was more likely to experience substitutional saturation, the mismatch analysis and Fu's $F_{\mathrm{S}}$ values were calculated from the Cyt $b$ data alone. The analyses used all haplotypes and the five haplogroups resolved in the MJN (Figure 3). The mismatch distribution for all haplotypes, group A and group $\mathrm{C}$, showed a unimodal distribution, indicating three recent demographic expansions (Figure $3(\mathrm{a}),(\mathrm{b}),(\mathrm{d})$, respectively). Thus, $H_{0 \text { eq }}$ was rejected, and $H_{\text {leq }}$ was assumed for $\mathrm{A}$ and $\mathrm{C}$. The expansion events were estimated to have occurred 0.21 MYA (95\% confidence interval $[\mathrm{CI}]=0.007-0.843 \mathrm{MYA}), 0.090 \mathrm{MYA}(\mathrm{CI}=$ 0.048-0.120 MYA) and 0.054 MYA (CI $=0.020-0.169$ MYA), respectively. These expansion events were further supported by significant Fu's $F_{\mathrm{S}}$ values (all haplotypes: $F_{\mathrm{S}}=$ -24.252, $P=0.001$; group A: $F_{\mathrm{S}}=-26.787, P=0.000$; group $C: F_{\mathrm{S}}=-7.879, P=0.001$; Figure $3(\mathrm{a})$, (b), (d), respectively). In contrast, both the mismatch distribution analyses and Fu's $F_{\mathrm{S}}$ values fit the expectation of demographic equilibrium for groups B, D and E (Figure 3(c), (e), (f), respectively). Thus, the $H_{0 \text { eq }}$ could not be rejected for these groups.

\subsection{Genealogical history}

Phylogenetic analyses of Cyt $b$ alone and the combined dataset yielded identical tree topologies. The Yarkand hare's haplotypes grouped into five major lineages (Figure 4), exactly corresponding to the five haplogroups (A, B, C, $\mathrm{D}$ and E) shown in the MJN (Figure 2). Phylogenetic inference based on D-loop sequences supported the monophyly of these five lineages, except for lineage $\mathrm{C}$ (tree not shown). Cyt $b$ sequence divergence (uncorrected pairwise distance; $p$-distance) among the 5 clades ranged from $0.7 \%$ to $2.3 \%$ (Table 4). As seen in Figure 4, E branched first, followed by $\mathrm{D}, \mathrm{C}$, and the terminal sister-grouping of B and A. The associations of these 5 lineages and the relationships among the 5 lineages were strongly supported $(\mathrm{BPP}=0.98-1.00$, Figure 4). Similar support was obtained from BS values on the NJ tree $(>70 \%$, Figure 4$)$, except for $\mathrm{C}(\mathrm{BS}=59 \%$, Figure 4).

Most haplotypes in lineages $\mathrm{A}$ and $\mathrm{C}$ were from North 


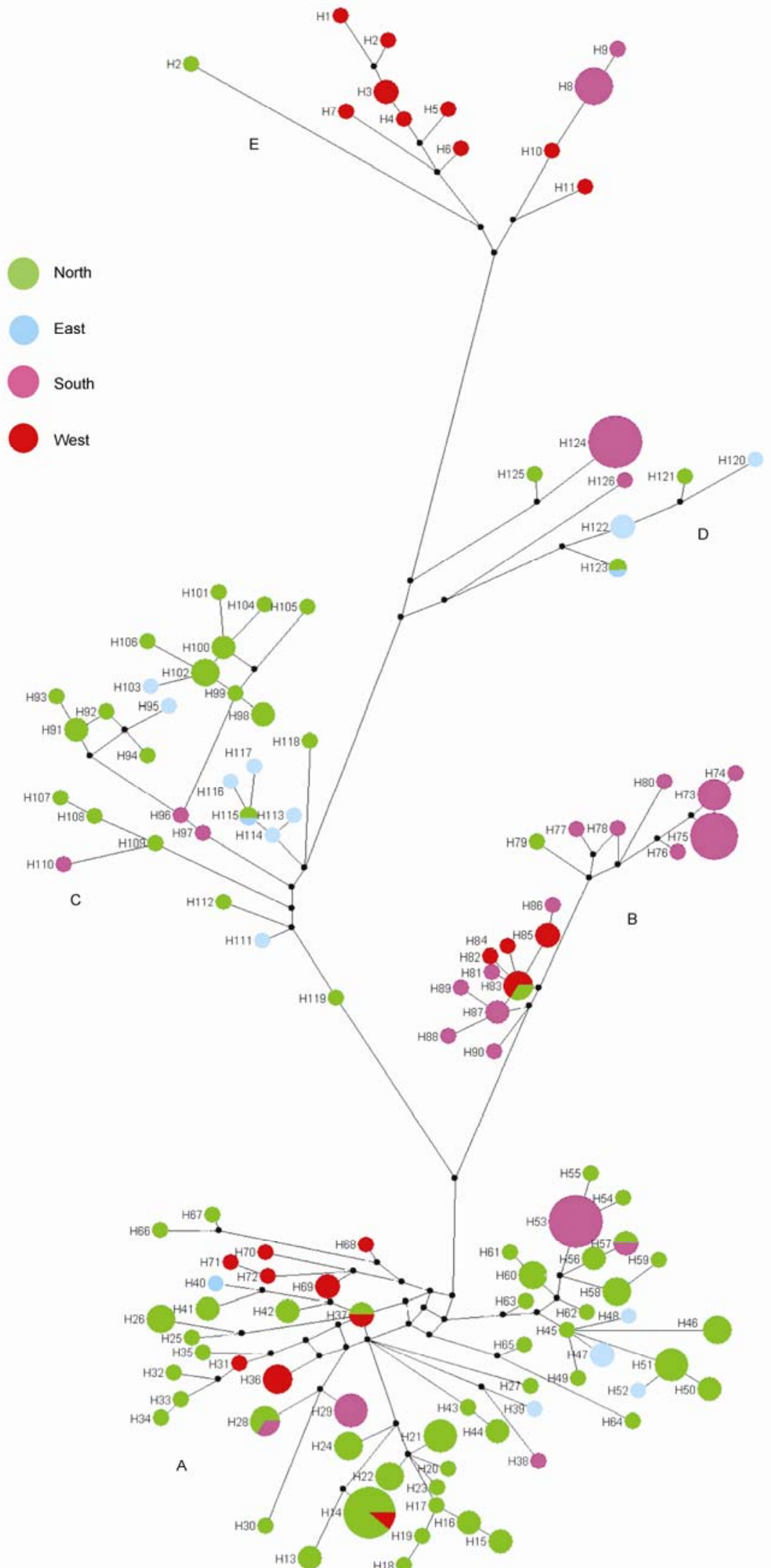

Figure 2 Median-joining network of the 126 mtDNA haplotypes based on the combined mtDNA fragments for the Yarkand hare, Lepus yarkandensis. Branches are generally proportional to the number of differences between haplotypes. Terminal locality abbreviations are mapped in Figure 1 and detailed in Table S1. 
Table 2 Analyses of molecular variance based on D-loop and Cyt b data for the Yarkand hare, Lepus yarkandensis ${ }^{\mathrm{a}}$

\begin{tabular}{ccccc}
\hline Source of variation & \multicolumn{2}{c}{ Percentage of variation (D-loop) } & Percentage of variation $($ Cyt $b)$ \\
\hline Among groups & $5.82^{* *}$ & $F_{\mathrm{CT}}=0.058^{* * *}$ & $11.28^{* * *}$ & $F_{\mathrm{CT}}=0.11^{* *}$ \\
Among populations within groups & $11.24^{* *}$ & $F_{\mathrm{SC}}=0.119^{* *}$ & $12.81^{* *}$ & $F_{\mathrm{SC}}=0.14^{* *}$ \\
Within populations & $82.94^{* *}$ & $F_{\mathrm{ST}}=0.171^{* *}$ & $75.90^{* *}$ & $F_{\mathrm{ST}}=0.24^{* *}$ \\
\hline
\end{tabular}

a) **, $P<0.01$.

Table 3 Pairwise $F_{\text {ST }}$ values among the four geographical groups of the Yarkand hare, Lepus yarkandensis, based on Cyt $b$ (below the diagonal) and D-loop data (above the diagonal) ${ }^{\text {a) }}$

\begin{tabular}{ccccc}
\hline Group & North & East & West & South \\
\hline North & & $0.111^{* *}$ & $0.089^{* *}$ & $0.120^{* *}$ \\
East & $0.110^{* * *}$ & & $0.130^{* *}$ & $0.108^{* * *}$ \\
West & $0.246^{* *}$ & $0.152^{* *}$ & & $0.066^{* *}$ \\
South & $0.186^{* *}$ & $0.121^{* *}$ & $0.104^{* *}$ & \\
\hline a**, $P<0.01$ & & & &
\end{tabular}

a) $* *, P<0.01$.

and East, and most haplotypes of B and E were from South and West. The phylogeographic tendency of lineage $\mathrm{D}$ remained unclear. Lineages $\mathrm{A}$ and $\mathrm{C}$ also contained a few haplotypes distributed in South or West, and lineages B and E included some haplotypes that occurred in North and East.

\section{Discussion}

\subsection{Haplotypic structure}

Populations from the combined northern and eastern areas of the Tarim Basin, and those from the combined southern and western areas, formed genetically and geographically distinct entities. The MJN and genealogical tree detected five distinct lineages of Yarkand hares, and the Cyt $b$ sequence divergence among them was substantial $(P$-distance $=0.7 \%-2.3 \%$ ). However, we did not find exclusive geographical structures corresponding to the 5 maternal lineages. Microevolutionary studies assume the null hypothesis that gene flow is unabated and this hypothesis cannot be rejected. When considering 20 populations, little geographical structure in the mtDNA variation was detected and this result was consistent with a previous study [42]. However, when the samples were combined into four geographical groups, phylogeographic differentiation was observed (Figure 2), and this structure was supported by pairwise $F_{\mathrm{ST}}$ values (Table 3 ). The lower pairwise $F_{\mathrm{ST}}$ values between North and East, and those between South and West compared with those between other combinations indicated genetic substructuring. This genetic differentiation was congruent with existing geographical barriers to dispersion. North and West are physically isolated by the Aksu and
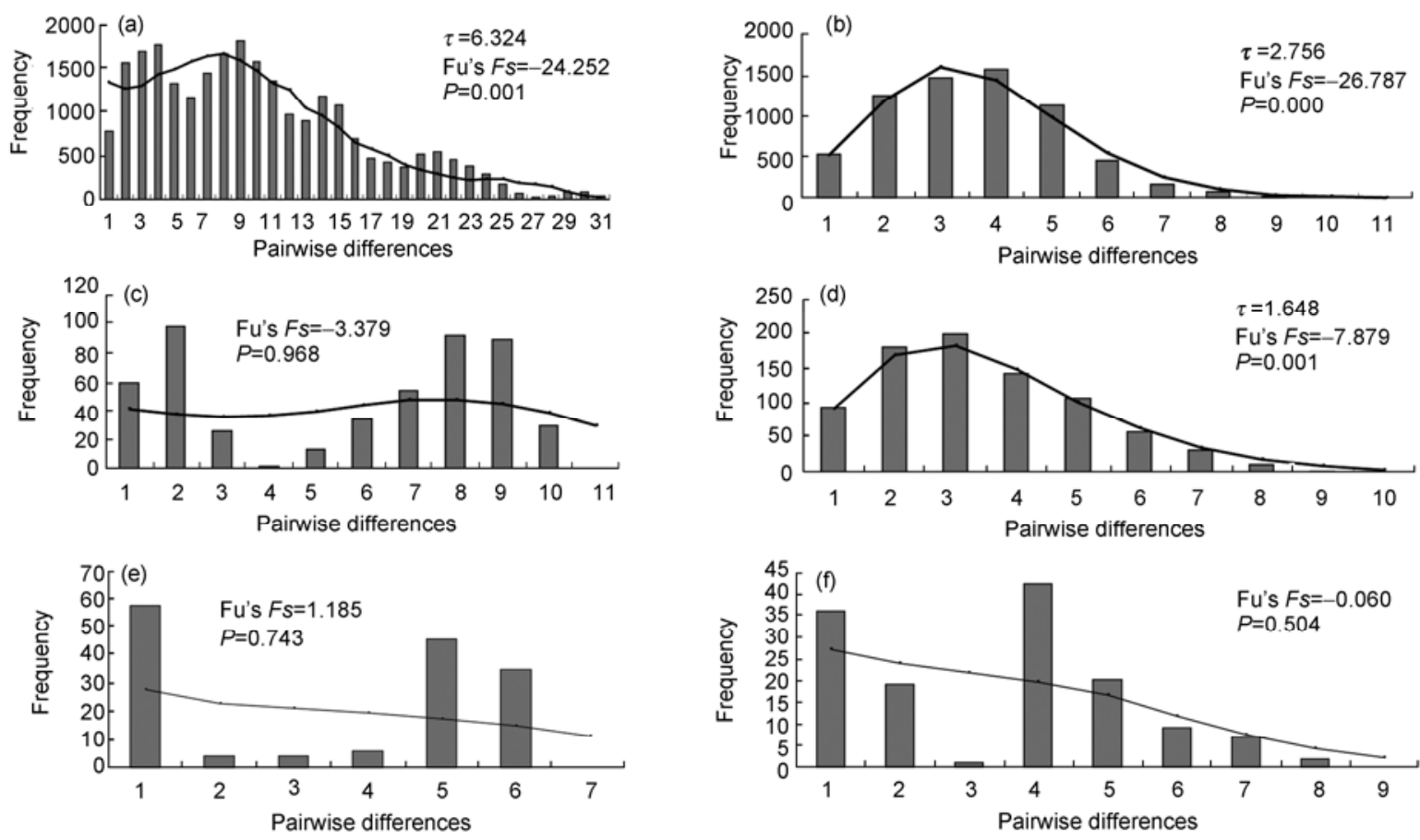

Figure 3 Observed (bars) and expected (solid lines) mismatch distributions from mtDNA Cyt b for the Yarkand hare, Lepus yarkandensis, along with Fu's $F_{\mathrm{S}}$ values for all haplotypes (a), haplotypes in group A (b), haplotypes in group B (c), haplotypes in group C (d), haplotypes in group D (e), and haplotypes in group E (f). Values of $\tau$, date of growth or decline, are measured in units of mutational time shown when the assumption of a sudden population expansion is not rejected. The statistical significance $(P)$ of Fu's $F_{\mathrm{S}}$ value is also presented. 
Table 4 Uncorrected pairwise distances (p-distance) among five lineages of the Yarkand hare based on Cyt $b$ data. The bold values on the diagonal indicate sequence divergence within a lineage.

\begin{tabular}{cccccc}
\hline Lineage & A & B & C & D & E \\
\hline A & $\mathbf{0 . 0 0 4}$ & & & & \\
B & 0.011 & $\mathbf{0 . 0 0 4}$ & & & \\
C & 0.007 & 0.010 & $\mathbf{0 . 0 0 3}$ & & \\
D & 0.010 & 0.014 & 0.008 & $\mathbf{0 . 0 0 3}$ & \\
E & 0.019 & 0.023 & 0.016 & 0.012 & $\mathbf{0 . 0 0 4}$ \\
\hline
\end{tabular}

Tarim rivers, and East and South are isolated by the Taklamakan Desert (Figure 1) [58]. The discovery of three haplotypes (H14, H37 and H83; Figure 2) shared between West and North, yet none shared between East and South, indicated that isolation between East and South was more complete than that between West and North.

Morphological evidence from the Yarkand hare is congruent with the genetic evaluation. An analysis of 24 cranial measurements using a one-way ANOVA analysis found that the southwestern population (PS) is generally separated from northern (KC, SY and YULI) and eastern (QM) populations [59]. The northern and eastern populations cannot be discriminated from each other morphologically. Thus, populations from the southwestern regions of the Tarim Basin and those from the northern plus eastern regions differ morphologically, and this corresponds to the genetic pattern.

\subsection{Glacial refugia and postglacial expansion}

Postglacial colonization can take the form of sequential dispersal into a newly available habitat by a few individuals. Populations in recently deglaciated regions should have relatively low genetic diversity compared with that in stable populations persisting in refugia, and colonizing populations should bear signatures of population expansion following the dispersal [2,60-62]. These predictions can be treated as a null hypothesis $\left(H_{0 \mathrm{gl}}\right)$, because glaciated areas will not have resident terrestrial vertebrates.

Western and southern regions of the Tarim Basin might contain one or more refugia used by the Yarkand hare during times of maximum glaciation. If true, then dispersal during interglacial times would occur from southwestern refugia towards the northeast as the glaciers retreated. The demographical history of the Yarkand hare in the northern and eastern Tarim Basin cannot reject the $H_{0 \mathrm{gl}}$. Mismatch distributions and Fu's $F_{\mathrm{S}}$ values suggest demographic expansion for the total group, and northeastern lineages $\mathrm{A}$ and C (Figure 3(a), (b), (d), respectively). In stark contrast, the $H_{0 \mathrm{gl}}$ is rejected for South and West (Figure 3(c), (f), respectively). These populations appear to be stable.

Population expansion time estimates for the total group and groups $\mathrm{A}$ and $\mathrm{C}$ are consistent with interglacial range expansion. The estimated date of 0.21 MYA for total hap- lotypes predates the Bulakebashi Valley glacier in the west Kunlun Mountains [29] (0.206 MYA). The estimated date of 0.090 MYA for group A and falls within the last interglacial period in the west Kunlun Mountains [29] (0.07-0.13 MYA). In addition, the estimated date of 0.054 MYA for group $\mathrm{C}$ falls in the interglacial period between the last glacial maximum [29] (0.016-0.025 MYA) and the Litian I glacier [29] (0.066 MYA) in the western Kunlun Mountains. If true, then the area must have contained several Pleistocene refugia, at least some of which are responsible for the evolution of distinctive maternal lineages.

The genealogical relationship of lineage A is consistent with the $H_{0 \mathrm{~g} \text {. }}$ The southwestern lineage $\mathrm{E}$ roots at the base of the tree, whereas northeastern lineage A is terminal, and this position enjoys strong support (Figure 4; BPP =0.98). Thus, populations from southwestern portions of the Tarim Basin have a relatively older evolutionary history. Furthermore, the D-loop's $\pi$ shows no significant differences among the four geographical groups, probably because of substitutional saturation-the D-loop has a higher evolutionary rate than Cyt $b$. However, Cyt $b$ 's $\pi$ for West $(0.011 \pm 0.006)$ and South $(0.010 \pm 0.005)$ is almost twice as high as that of the North $(0.005 \pm 0.003)$ and East $(0.006 \pm 0.003)$. Northeastern populations have relatively less genetic diversity. Therefore, it is likely that the distribution of the Yarkand hare contracted to southwestern parts of the Tarim Basin during glacial maxima, and then recolonized or expanded into the northeast during the interglacial periods. This is similar to the rapid recolonization by many species in temperate Europe and North America [2,8]. Given the relatively complete geographic isolation between East and South, postglacial dispersal to the East likely occurred via the North.

This demographical history is further supported by the evidence from gene flow. The AMOVA results show that only $5.82 \%$ of the variation in the D-loop and $11.28 \%$ in Cyt $b$ lies between geographical groups. Most of the variation $(82.94 \%$ in control region and $75.90 \%$ in Cyt $b$ ) is attributable to intrapopulational diversity (Table 2). This indicates extensive gene flow. Long distance gene flow is evidenced by the fact that all four geographical groups contain a mix of haplotypes, although some haplotypes dominate in different geographical areas (Figure 2). Wu et al. [42] reported similar results. Although hares are capable of very rapid locomotion, extensive, long distance dispersal is unlikely to account for our findings. The pattern of broadly mixed haplotypes suggests a recent common history of colonization, which is also congruent with our inference for the demographical history of the Yarkand hare.

The $H_{0 \mathrm{gl}}$ is also supported by geological evidence. Given that the Tarim Basin probably did not have Quaternary glaciers [27-32], why did only the southwestern Tarim Basin contain refugia during glacial events, if the northeast was also not glaciated? The Tarim Basin is located north of the Qinghai-Tibetan Plateau. Uplifting of the Qinghai-Tibetan 


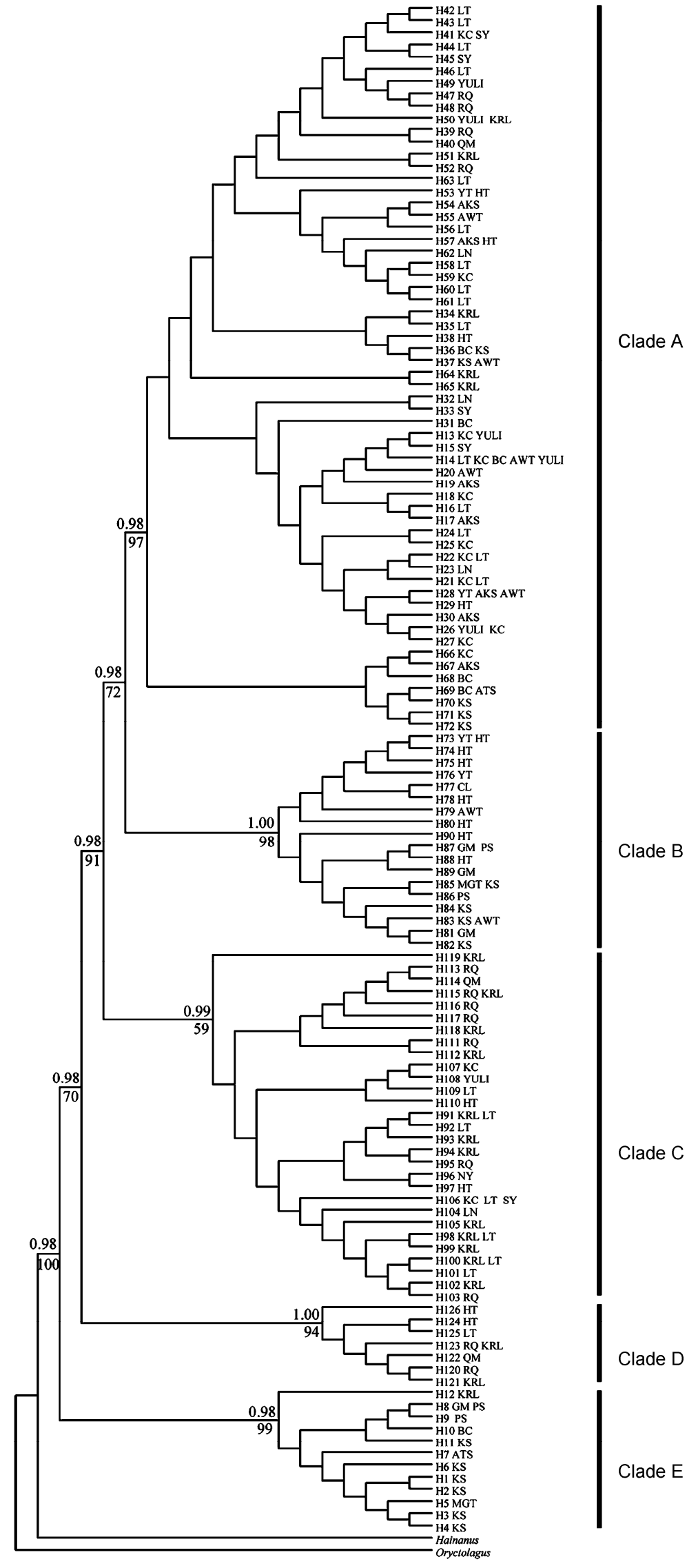

Figure 4 Bayesian inference tree from 126 mtDNA haplotypes based on combined mtDNA Cyt $b$ and D-loop fragments. The optimal evolutionary model is TIM $+\mathrm{I}+\mathrm{G}$ and the tree is rooted with Lepus hainanus and Oryctolagus cuniculus. Numbers above the branches are Bayesian posterior probabilities and those below the branches are the bootstrap proportions derived from a neighbor-joining tree. The geographic distributions of the haplotype are included in the sequence names, and these are mapped in Figure 1 and detailed in Table S1. 
Plateau during the Tertiary and Quaternary prevented the flow of humid Indian monsoons from passing through the Himalayas into the basin, thus contributing to the extreme aridity [63-67]. Ecologically, water is the most limiting factor for plant growth in arid environments. The spatio-temporal dynamics of vegetation are, therefore, largely determined by available water [68-73]. Not surprisingly, biotic diversity is concentrated in riparian areas [74,75].

During interglacial times, the average annual precipitation in the Tarim Basin was very limited ( 17.4-33.6 mm). Meltwater rivers from glaciers in the Tianshan and Kunlun mountains in the southwest (Figure 1) served as the dominant sources of water. However, the meltwater greatly decreased at times of maximum glaciation because the climate was colder and drier [76]. Total river flow declined from the southwest towards the northeast to the extent that the middle and lower reaches dried up, and yet the upper reaches near the glaciers were not greatly influenced, as evidenced from the Keriya [76] (Figure 1) and Tarim rivers [25,77-80] (Figure 1). For example, today, the 1321-km long Tarim River is the world's longest intra-continental river in a desert system. It runs eastward across the northern Tarim Basin to the eastern Tarim Basin and waters the biota in its drainage area. However, during glacial times, northern and eastern portions of the river dried up and its associated biota must have either died or retreated to the southwest. The subsequent interglacial periods were relatively warm and wet; therefore, organisms probably recolonized the northeast as glacial meltwater increased and the rivers reoccupied their courses. Certainly, higher species diversity occurred in southwestern Tarim Basin in ancient times, as evidenced by a large number of ancient oases and the occurrence of a large variety of pollens $[68,81]$. This pattern supports the concept of the southwestern Tarim Basin being a glacial refugium.

\subsection{Conservation implications}

Our study not only provides insights into the evolutionary history of the Yarkand hare, but also helps to identify conservation units for this threatened species. Traditionally, subspecies have been recognized on the basis of discontinuities in the geographical distribution of phenotypic traits [82], and they have been treated as separate conservation units in conservation biology and management plans [83]. However, increasing molecular studies failed to identify traditional subspecies as being phylogenetically diagnosable [82-87], and philosophically their recognition can be a problem [88]. A conservation unit might also consider congruence among morphological characters, genetic patterns, ecology, and physiology, for example. From this perspective, the Yarkand hare could be divided into two conservation units: one for the populations from North and East and the other from the South and West. Management plans for these two conservation units would be expected to effec- tively prevent extirpation on both groups and the concomitant loss of genetic diversity.

The extent of genetic and morphological diversity suggests that any consideration of population augmentation via translocations must be made cautiously. Although it may be desirable to manage genetic diversity within areas, a shift of genotypic frequency could be disastrous if haplotypic diversity reflects adaptation. Further, the ecosystems of the northern and eastern Tarim Basin are more vulnerable to habitat degradation by way of water resource utilization than those in the southwest. Special attention should be paid to the northeastern region. Although the Yarkand hare has been listed in the Second Category of State Key Protected Wildlife List (1988) and the 1996 IUCN Red List of Threatened Animals [35], management strategies should focus on maintaining ecosystem stability and not just protecting named taxa.

In the QTP, Europe, and North America, glacial advance drove organisms into refugia. However, in the Tarim Basin, their retreat reflected available water. In the Tarim Basin, refugia may have existed not only during glacial periods, but also other times when the water supply was not sufficient to sustain ecosystems. Recent damming and agricultural exploitation of water in the Tarim River has resulted in the loss of the natural flora in large areas of the river's lower reaches. Although water recharging in the lower reaches has restored the natural vegetation on a large scale as the groundwater level rose [80,81], this strategy may not result in long-term ecosystem stability, especially given mounting economic and agricultural pressures. Therefore, management strategies should also include the return of farmland to natural forests or grasslands, in key areas. Water resources should be carefully managed. Most importantly, new laws must be enacted to guarantee that management strategies are put in practice.

\section{Conclusion}

Postglacial colonization of the Tarim Basin by the endemic Yarkand hare was assessed by range-wide sampling. Populations from the northern and eastern Tarim Basin shared a similar history, as did those from the western and southern regions. Refugia likely existed in the southwestern Tarim Basin at times of maximum glaciation. The present distribution of the Yarkand hare probably resulted from at least three postglacial colonization events which occurred about $0.21,0.090$, and 0.054 MYA. Significantly, availability of water, rather than displacement by glaciers, was the dominant driving force for the retreat of the Yarkand hare to refugia. This differed from the dynamic mechanism for refugia occupation in Europe, North America, and the QTP in China, i.e., glacial displacement. Investigations of other species, especially plants, would be essential to determine if this new dynamic mechanism has a general significance for 
arid species. Nevertheless, this discovery has important implications for conservation.

We specially thank MIAO YongWang for his assistance in data analysis and MA De for helping with sample collection. This work was supported by the National Key Basic Research Program of China (2007CB411600), the National Natural Science Foundation of China (30500061 and 31060152), the Research Start-up Fund of Xinjiang Uighur Autonomous Region for Young Teachers in University (XJEDU2008S03), and the College-University United Project of Xinjiang University (XY080117).

1 Avise J C, Walker D, Johns G C. Speciation durations and Pleistocene effects on vertebrate phylogeography. Proc R Soc Lond B Biol Sci, 1998, 265: 1707-1712

2 Hewitt G M. Some genetic consequences of ice ages, and their role in divergence and speciation. Biol J Linn Soc, 1996, 58: 247-276

3 Hewitt G M. Speciation, hybrid zones and phylogeography or seeing genes in space and time. Mol Ecol, 2001, 10: 537-549

4 Petit R J, Pineau E, Demesure B, et al. Chloroplast DNA footprints of postglacial recolonization by oaks. Proc Natl Acad Sci USA, 1997, 94: 9996-10001

5 Abbott R J, Smith L C, Milne R I, et al. Molecular analysis of plant migration and refugia in the Arctic. Science, 2000, 289: 1343-1346

6 Weider L J, Hobæk A. Phylogeography and Arctic biodiversity: A review. Ann Zool Fenn, 2000, 37: 217-231

7 Abbott R J, Brochmann C. History and evolution of the arctic flora: In the footsteps of Eric Hultén. Mol Ecol, 2003, 12: 299-313

8 Hewitt G M. Genetic consequences of climatic oscillations in the Quaternary. Proc R Soc Lond B Biol Sci, 2004, 359: 183-195

9 Weir J T, Schluter D. Ice sheets promote speciation in boreal birds. Proc R Soc Lond B Biol Sci, 2004, 271: 1881-1887

10 Petit R J, Hampe A, Cheddadi R. Climate changes and tree phylogeography in the Mediterranean. Taxon, 2005, 54: 877-885

11 Waltari E, Cook J A. Hares on ice: Phylogeography and historical demographics of Lepus arcticus, L. othus, and L. timidus (Mammalia: Lagomorpha). Mol Ecol, 2005, 14: 3005-3016

12 Anderson L L, Hu F S, Nelson D M, et al. Ice-age endurance: DNA evidence of a white spruce refugium in Alaska. Proc Natl Acad Sci USA, 2006, 103: 12447-12450

13 Soltis D E, Morris A B, Lachlan J M, et al. Comparative phylogeography of unglaciated eastern North America. Mol Ecol, 2006, 15: 4261-4293

14 Shen L, Chen X Y, Li Y Y. Glacial refugia and postglacial recolonization patterns of organisms. Acta Ecol Sin, 2002, 22: 1983-1990

15 Qu Y H, Ericson P G P, Lei F M, et al. Postglacial colonization of the Tibetan plateau inferred from the matrilineal genetic structure of the endemic red-necked snow finch, Pyrgilauda ruficollis. Mol Ecol, 2005, 14: 1767-1781

16 Zhang Q, Chiang T, George M, et al. Phylogeography of the Qinghai-Tibetan Plateau endemic Juniperus przewalskii (Cupressaceae) inferred from chloroplast DNA sequence variation. Mol Ecol, 2005, 14: 3513-3524

17 Meng L, Yang R, Abbott R J, et al. Mitochondrial and chloroplast phylogeography of Picea crassifolia Kom. (Pinaceae) in the Qinghai-Tibetan Plateau and adjacent highlands. Mol Ecol, 2007, 16: $4128-4137$

18 Chen S, Wu G, Zhang D, et al. Potential refugium on the Qinghai-Tibet Plateau revealed by the chloroplast DNA phylogeography of the alpine species Metagentiana striata (Gentianaceae). Bot J Linn Soc, 2008, 157: 125-140

19 Yang F S, Li Y F, Ding X, et al. Extensive population expansion of Pedicularis longiflora (Orobanchaceae) on the Qinghai-Tibetan Plateau and its correlation with the Quaternary climate change. Mol
Ecol, 2008, 17: 5135-5145

20 Wang L Y, Abbott R J, Zheng W, et al. History and evolution of alpine plants endemic to the Qinghai-Tibetan Plateau: Aconitum gymnandrum (Ranunculaceae). Mol Ecol, 2009, 18: 709-721

21 Zhang D R, Chen M Y, Murphy R W, et al. Genealogy and palaeodrainage basins in Yunnan Province: Phylogeography of the Yunnan spiny frog, Nanorana yunnanensis (Dicroglossidae). Mol Ecol, 2010, 19: 3406-3420

22 Che J, Zhou W W, Hu J S, et al. Spiny frogs (Paini) illuminate the history of the Himalayan region and Southeast Asia. Proc Natl Acad Sci USA, 2010, 107: 13765-13770

23 Chen Y N, Wang Q, Ruan X, et al. Physiological response of Populus euphratica to artificial water-recharge of the lower reaches of Tarim River. J Integr Plant Biol, 2004, 46: 1393-1401

24 Chen Y N, Zhang X L, Zhu X M, et al. Analysis on the ecological benefits of the stream water conveyance to the dried-up river of the lower reaches of Tarim River, China. Sci China Ser D, 2004, 47: 1053-1064

25 Naumburg E, Mata-Gonzalez R, Hunter R G, et al. Phreatophytic vegetation and groundwater fluctuations: A review of current research and application of ecosystem response modeling with an emphasis on Great Basin vegetation. Environ Manage, 2005, 35: 726740

26 Zhuang L, Chen Y N. Physiological responses of three contrasting plant species to groundwater level changes in an arid environment. J Integr Plant Biol, 2006, 48: 520-526

27 Brantingham P J, Olsen J W, Schaller G B. Lithic assemblages from the Chang Tang region, Northern Tibet. Antiquity, 2001, 75: 319327

28 Brantingham P J, Ma H, Olsen J W, et al. Speculation on the timing and nature of Late Pleistocene hunter-gatherer colonization of the Tibetan Plateau. Chinese Sci Bull, 2003, 48: 1510-1516

29 Zheng B, Xu Q, Shen Y. The relationship between climate change and Quaternary glacial cycles on the Qinghai-Tibetan Plateau: Review and speculation. Quat Int, 2002, 97-98: 93-101

30 Owen L A, Finkel R C, Zhou M H, et al. Late Quaternary landscape evolution in the Kunlun Mountains and Qaidam Basin, Northern Tibet: A framework for examining the links between glaciation, lake level changes and alluvial fan formation. Quat Int, 2006, 154-155: 73-86

31 Kong P, Fink D, Na C G, et al. Late Quaternary glaciation of the Tianshan, Central Asia, using cosmogenic ${ }^{10} \mathrm{Be}$ surface exposure dating. Quat Res, 2009, 72: 229-233

32 Zhao J D, Liu S Y, He Y Q, et al. Quaternary glacial chronology of the Ateaoyinake River Valley, Tianshan Mountains, China. Geomorphology, 2009, 103: 276-284

33 Luo Z X. The Chinese Hare. Beijing: China Forestry Publishing House, 1988

34 Gao Y T. Current studies on the Chinese Yarkand hare. Ann Zool Fenn, 1983, 174: 23-25

35 Wang S. China Red Data Book of Endangered Animals. Beijing: Science Press, 1998

36 Pierpaoli M, Riga F, Trocchi V, et al. Species distinction and evolutionary relationships of the Italian hare (Lepus corsicanus) as described by mitochondrial DNA sequencing. Mol Ecol, 1999, 8: 1805-1817

37 Wu C H, Wu J P, Bunch T D, et al. Molecular phylogenetics and biogeography of Lepus in Eastern Asia based on mitochondrial DNA sequences. Mol Phylogenet Evol, 2005, 37: 45-61

38 Matthee C A, Van Vuuren B J, Bell D, et al. A molecular supermatrix of the rabbits and hares (Leporidae) allows for the identification of five intercontinental exchanges during the Miocene. Syst Biol, 2004, 53: 433-447

39 Melo-Ferreira J, Boursot P, Suchentrunk F, et al. Invasion from the cold past: Extensive introgression of mountain hare (Lepus timidus) mitochondrial DNA into three other hare species in northern Iberia. 
Mol Ecol, 2005, 14: 2459-2464

40 Melo-Ferreira J, Boursot P, Randi E, et al. The rise and fall of the mountain hare (Lepus timidus) during Pleistocene glaciations: Expansion and retreat with hybridization in the Iberian Peninsula. Mol Ecol, 2007, 16: 605-618

41 Li Z C, Xia L, Li Y M, et al. Mitochondrial DNA variation and population structure of the Yarkand hare Lepus yarkandensis. Acta Theriol, 2006, 51: 243-253

42 Wu Y H, Xia L, Zhang Q, et al. Habitat fragmentation affects genetic diversity and differentiation of the Yarkand hare. Conserv Genet, 2010, 11: 183-194

43 Sambrook J, Fritsch E F, Maniatis T. Molecular Cloning: A Laboratory Manual. 2nd ed. Cold Spring Harbor: Cold Spring Harbor Laboratory Press, 1989

44 Altschul S F, Madden T L, Schäffer A A, et al. Gapped BLAST and PSI-BLAST: A new generation of protein database search programs. Nucleic Acids Res, 1997, 25: 3389-3402

45 Thompson J D, Gibson T J, Plewniak F, et al. The ClustalX windows interface: Flexible strategies for multiple sequence alignment aided by quality analysis tools. Nucleic Acids Res, 1997, 24: 4876-4882

46 Excoffier L, Laval G, Schneider S. Arlequin version 3.0: An integrated software package for population genetics data analysis. Evol Bioinform Online, 2005, 1: 47-50

47 Bandelt H J, Forster P, Rohl A. Median-joining networks for inferring intraspecific phylogenies. Mol Biol Evol, 1999, 16: 37-48

48 Cassens I, Mardulyn P, Milinkovitch M C. Evaluating intraspecific 'network' construction methods using simulated sequence data: Do existing algorithms outperform the global maximum parsimony approach? Syst Biol, 2005, 54: 363-372

49 Excoffier L, Smouse P E, Quattro J M. Analysis of molecular variance inferred from metric distances among DNA haplotypesapplication to human mitochondrial-DNA restriction data. Genetics, 1992, 131: 479-491

$50 \mathrm{Fu}$ Y X. Statistical tests of neutrality of mutations against population growth, hitchhiking and background selection. Genetics, 1997, 147: 915-925

51 Rogers A R, Harpending H C. Population growth makes waves in the distribution of pairwise genetic differences. Mol Biol Evol, 1992, 9: 552-569

52 Ronquist F, Huelsenbeck J P. MrBayes 3: Bayesian phylogenetic inference under mixed models. Bioinformatics, 2003, 19: 1572-1574

53 Posada D, Crandall K A. Modeltest: Testing the model of DNA substitution. Bioinformatics, 1998, 14: 817-818

54 Akaike $\mathrm{H}$. A new look at the statistical model identification. IEEE T Automat Contr, 1974, 19: 716-723

55 Huelsenbeck J P, Bollback J P. Empirical and hierarchical Bayesian estimation of ancestral states. Syst Biol, 2001, 50: 351-366

56 Leaché A D, Reeder T W. Molecular systematics of the Eastern Fence lizard (Sceloporus undulatus): A comparison of parsimony, likelihood, and Bayesian approaches. Syst Biol, 2002, 51: 44-68

57 Tamura K, Dudley J, Nei M, et al. MEGA4: Molecular Evolutionary Genetics Analysis (MEGA) software version 4.0. Mol Biol Evol, 2007, 24: 1596-1599

58 Johns G C, Avise J C. A comparative summary of genetic distances in the vertebrates from the mitochondrial cytochrome $b$ gene. Mol Biol Evol, 1998, 15: 1481-1490

59 Aerziguli S, Mairepati P, Dilixiati A, et al. The comparison of skull morphology of Yarkand hare (Lepus yarkandensis) different geographical populations. Xinjiang Agricul Sci, 2010, 47: 1627-1631

60 Hewitt G M. Post-glacial re-colonization of European biota. Biol J Linn Soc, 1999, 68: 87-112

61 Lessa E P, Cook J A, Patton J L. Genetic footprints of demographic expansion in North America, but not Amazonia, during the late Quaternary. Proc Natl Acad Sci USA, 2003, 100: 10331-10334

62 Galbreath K, Cook J A. Genetic consequences of Pleistocene glaci- ations for the tundra vole (Microtus oeconomus) in Beringia. Mol Ecol, 2004, 13: 135-148

63 Zhu Z, Wu Z, Liu S, et al. An Outline of Chinese Deserts. Beijing: Science Press, 1980

64 Ren M. An Outline of the Physical Geography in China. Beijing: Commercial Publisher, 1980

65 Shi Y, Li J, Li B. Uplift and Environmental Changes of Qinghai-Xizang (Tibetan) Plateau in the Late Cenozoic. Guangzhou: Guangdong Science \& Technology Press, 1998

66 Sun J M, Liu T S. The age of the Taklimakan Desert. Science, 2006, 312: 1621

67 Sun J M, Zhang L Y, Deng C L, et al. Evidence for enhanced aridity in the Tarim Basin of China since 5.3Ma. Quat Sci Rev, 2008, 27: 1012-1023

68 Li X, Lu L, Cheng G D, et al. Quantifying landscape structure of the Heihe River Basin, north-west China using FRAGSTATS. J Arid Environ, 2001, 48: 521-535

69 Elmore A J, Manning S J, Mustard J F, et al. Decline in alkali meadow vegetation cover in California: The effects of groundwater extraction and drought. J Appl Ecol, 2006, 43: 770-779

70 Puckridge J T, Sheldon F, Walker K F, et al. Flow variability and the ecology of arid zone rivers. Mar Freshw Res, 1998, 49: 55-72

71 Puckridge J T, Walker K F, Costelle J F. Hydrological persistence and the ecology of dryland rivers. Regul River, 2000, 16: 385-402

72 Sear D A, Armitage P D, Dawson F H. Groundwater dominated rivers. Hydrol Process, 1999, 13: 255-276

73 Pettit N E, Friend R H, Davis P M. Identifying the natural flow regime and the relationship with riparian vegetation for two contrasting western Australian rivers. Regul River, 2001, 17: 201-215

74 Davies B R, Thoms M C, Walker K F, et al. Dryland rivers: Their ecology, conservation and management. In: Calow P, Petts G E, eds. The River Handbook, Vol. 2. Oxford: Blackwell Scientific Publication, 1994. 484-512

75 Walker K F, Sheldon F, Puckridge J T. A perspective on dryland river system. Regul River, 1995, 11: 85-104

76 Yang X P, Zhu Z D, Jaekel D, et al. Late Quaternary palaeoenvironment change and landscape evolution along the Keriya River, Xinjiang, China: The relationship between high mountain glaciation and landscape evolution in foreland desert regions. Quat Int, 2002, 97-98: 155-166

77 Chen Y N, Chen Y P, Li W H, et al. Response of the accumulation of proline in the bodies of Populus euphratica to the change of groundwater level at the lower reaches of Tarim River. Chinese Sci Bull, 2003, 48: 1995-1999

78 Chen Y N, Li W, Xu H L, et al. The influence of groundwater on vegetation in the lower reaches of Tarim River, China. Acta Geogr Sin, 2003, 58: 542-549

79 Chen Y N, Zilliacus H, Li W H, et al. Ground-water level affects plant species diversity along the lower reaches of the Tarim river, Western China. J Arid Environ, 2006, 66: 231-246

80 Hou P, Beeton R J S, Carter R W, et al. Response to environmental flows in the lower Tarim River, Xinjiang, China: Ground water. J Environ Manage, 2007, 83: 371-382

81 Fan Z L, Ma Y J, Ji F, et al. Relations between exploitationutilization of water resources and oasis evolution and ecological balance in Tarim Basin. J Nat Resour, 2001, 16: 22-26

82 Mayr E, Ashlock P D. Principles of Systematic Biology. New York: McGraw-Hill, 1991

83 O'Brien S J, Mayr E. Bureaucratic mischief: Recognizing endangered species and subspecies. Science, 1991, 251: 1187-1188

84 Barrowclough G F. Genetic and phenotypic differentiation in a wood warbler (genus Dendroica) hybrid zone. Auk, 1980, 97: 655-668

85 Ball R M, Avise J C. Mitochondrial DNA phylogeographic differentiation among avian populations and the evolutionary significance of subspecies. Auk, 1992, 109: 626-636 
86 Burbrink F T, Lawson R, Slowinski J B. Mitochondrial DNA phylogeography of the polytypic North American rat snake (Elaphe $o b$ soleta): A critique of the subspecies concept. Evolution, 2000, 54: 2107-2118
87 Fischer A, Pollack J, Thalmann O, et al. Demographic history and genetic differentiation in Apes. Curr Biol, 2006, 16: 1133-1138

88 Frost, D R, Hillis D M. Species in concept and practice: herpetological applications. Herpetologica, 1990, 46: 87-104

Open Access This article is distributed under the terms of the Creative Commons Attribution License which permits any use, distribution, and reproduction in any medium, provided the original author(s) and source are credited.

\section{Supporting Information}

Table S1 Specimens examined in this study. Collection and voucher specimen information for populations of the Yarkand hare (Lepus yarkandensis)

The supporting information is available online at csb.scichina.com and www.springerlink.com. The supporting materials are published as submitted, without typesetting or editing. The responsibility for scientific accuracy and content remains entirely with the authors. 